\title{
$\mathrm{CBRP}$ 기반 잔여전력량을 이용한 개선된 클러스터 라우팅 기법
}

\author{
박 혜 란*, 김 우 완**, 장 상 동***

\section{Improved Cluster Routing Algorithm Using Remaining Electric Energy Based on CBRP}

\author{
Hyeran Park*, Wuwoan Kim*, Sangdong Jang***
}

\begin{abstract}
요 약
클러스터 기반 라우팅 프로토콜(CBRP, Cluster-Based Routing Protocol)은 각 클러스터 내에 헤더를 선출 하고 클러스터 헤더가 모든 이동 노드들을 관리, 운영하기 때문에 전력 소모가 심하게 일어나게 된다. 각 노드의 잔 여전력량을 고려하지 않고 헤더를 임의로 선출하기 때문에 클러스터 헤더의 평균 수명이 짧아지고 빈번하게 다른 헤더를 선출해야 하는 문제점을 가지고 있다. 본 논문에서는 잔여전력량을 고려하여 헤더 재선출로 인한 라우팅 지 연을 줄이고, 클러스터뿐만 아니라 전체 네트워크의 수명을 연장시키는 새로운 헤더 선출 기법을 제안한다. 제안 기 법에서는 잔여전력량을 고려하여 헤더와 보조 헤더를 선출한다. 선출된 클러스터 헤더의 잔여전력량이 낮아져 헤더 역할을 수행할 수 없게 되면 미리 선출해둔 보조 헤더가 클러스터 헤더 역할을 수행하도록 함으로써 빈번한 헤더 재선출로 인한 문제점을 줄인다. 또한 잔여전력량이 높은 노드가 헤더로 선출되기 때문에 각 클러스터의 모든 노드 는 전력이 균등하게 소비되어 네트워크 전체의 수명을 연장시킨다.
\end{abstract}

- Keywords : 클러스터 기반 라우팅 프로토콜, 애드 혹 네트워크, 클러스터 헤더 선출 기법

\begin{abstract}
In the Cluster-Based Routing Protocol (CBRP) a cluster header in each cluster should be elected. The cluster headers consume energy much more than other member nodes do because they manage and operate all of mobile nodes in their cluster. The traditional CBRP elects a cluster header without considering the remaining electric energy of each node. So, there exist problems that the cluster header has short average lifetime, and a new cluster header should be elected

- 제1저자 : 박혜란 - 교신저자 : 김우완

- 투고일 : 2012. 11. 15, 심사일 : 2012. 11. 27, 게재확정일 : 2012. 12. 8.

* 경남대학교 첨단공학과 석사과정(Dept. of Advanced Engineering, Kyungnam Univ., Master Student)

** 경남대학교 컴퓨터공학과 교수(Dept. of Computer Engineering, Kyungnam Univ., Professor)

*** 경남대학교 컴퓨터공학과 조교수(Dept. of Computer Engineering, Kyungnam Univ., Assistant Professor)

※ 본 연구는 2012학년도 경남대학교 학술연구 장려금 지원으로 수행되었음
\end{abstract}


again frequently. In this paper, we propose the improved protocol which prolongs the lifetime of the cluster header, decreases the problem of re-electing the cluster header and enhances the stability of the path. In order to achieve this, when a cluster header is elected in a cluster, the remaining electric energies of all the nodes are compared with one another, and the node with the highest energy is elected as the cluster header. Also, the node with the second highest energy is elected as the second header. If the elected cluster header is unable to perform the role of the cluster header any more because the remaining energy level goes low, it sends a beacon message to neighbor member nodes, then the second header will serve as the cluster header.

\section{- Keywords : Cluster-Based Routing Protocol, Ad-Hoc Network, Scheme of Electing Cluster Header}

\section{I. 서 론}

현재 대부분의 무선이동통신 분야는 기반(infrastructure) 네트워크에 기초해 있다. 그렇지만 기반 네트워크가 갖추어지지 않은 전쟁터, 재난구조지역, 산간지역 등에서의 통신을 위해서 는 종단 시스템 사이의 직접적인 통신이 필요할 수 있다. 종단 시스템 사이의 직접적인 통신을 위해 개발되어진 네트워크가 바로 이동 애드 혹 네트워크(Ad hoc Network)이다[1].

애드 혹 네트워크의 라우팅 방법은 Proactive, Reactive 와 두 방법을 혼합한 Hybrid 방법으로 분류 된다.

Proactive 방법은 미리 경로 정보를 유지하여, 전송할 패킷 이 발생할 경우 별도의 경로 탐색 과정 없이 바로 전송할 수 있다. 이 방법은 주기적으로 제어 패킷을 전송하여 경로를 미리 유지하므로 라우팅 오버헤드가 상대적으로 크지만, 별도의 경 로 탐색 과정을 거치지 않으므로 경로 설정 지연 시간이 짧다. 하지만 이동성이 잦은 경우 변경된 라우팅 테이블을 계속적으 로 변경해야 하므로 효과적이지 못하다. 대표적인 방법으로는 DSDV(Destination Sequenced Distance Vector)[2]가 있다.

Reactive 방법은 경로 정보를 갱신하지 않고 있다가 전송 할 패킷이 발생했을 때 경로 탐색을 시작한다. 패킷이 발생할 때만 경로를 탐색하므로 노드의 이동성이 있는 상황에서 에너 지 효율적이다. 하지만 이동성이 잦은 경우 경로 탐색 과정의 실패로 반복적인 경로 탐색 패킷에 의해 에너지 소모가 더 커 진다. 대표적인 방법으로 $\mathrm{AODV}(\mathrm{Ad}$ hoc On-demand Distance Vector)[3], DSR(Dynamic Source Routing) [4] 등이 있다.
Proactive 방법과 Reactive 방법을 혼합한 Hybrid 방법 은 각 노드가 사전에 정해진 홉 거리만큼 이웃 노드의 라우팅 정보를 유지하고 홉 거리를 넘어서는 노드에 대해서만 경로 설 정 절차를 요구하는 방법이다. 대표적인 방법에는 $\mathrm{ZRP}$ (Zone Routing Protocol)[5], TORA(Temporally-Ordered Routing Algorithm) [6], CBRP(Cluster Based Routing Protocol)[7] 등이 있다.

애드 혹 네트워크는 고정된 하부구조가 없기 때문에 이동 노드들 끼리 데이터를 전달 할 수 있어야 하는데 이러한 이동 노드는 전파 도달 거리가 제한되어 중간 노드들이 데이터 전 달 기능을 가지며, 이동 노드들은 제한된 에너지로 동작해야 하기 때문에 효율적인 알고리즘을 적용하여 최소의 자원을 사 용한 최대의 성능을 목표로 한다[8].

현재 에너지 수준이 낮은 노드가 높은 트래픽을 라우팅하 게 되면 해당 노드의 배터리 잔여전력량이 점점 작아져서 끝 내는 이 노드를 경유하는 모든 경로들을 사용할 수 없게 된다. 따라서 노드들의 에너지 상태를 고려하여 경로를 선택해야 안 정적인 데이터 전송이 가능하다. 효율적인 에너지 사용 또는 에너지를 절약할 수 있는 매커니즘 등이 근본적인 문제와 함 께 고려되어야 한다. 이런 무선 네트워크 환경에서 소비되는 에너지양을 줄이기 위한 대표적인 프로토콜로 $\mathrm{CBRP}$ 가 있다.

$\mathrm{CBRP}$ 는 효율적인 에너지 사용을 위해 이동 노드들을 클 러스터 단위로 나누고 각 클러스터 내에서 클러스터 헤더를 선출한 후 헤더가 클러스터 멤버들을 관리, 운영한다. 클러스 터 헤더의 에너지가 고갈 될 경우 클러스터 내의 모든 이동 노드들은 새로운 헤더가 선출될 때까지 수행을 멈추게 되어 전체 네트워크의 성능을 저해하는 문제점을 가지고 있다 [9] [10] [11].

이러한 문제점을 개선하기 위해 에너지를 고려하여 가장 
높은 잔여전력량을 가진 노드를 헤더로 선출하고, 선출된 헤 더의 클러스터 내에서 두 번째로 높은 잔여전력량을 가진 노 드를 보조 헤더로 선출한다. 헤더의 에너지가 고갈 될 경우 보조 헤더로 헤더의 역할을 신속히 넘겨 끊김없는 데이터 전 송을 가능하게 하고, 재선출 횟수를 줄임으로써 네트워크 성 능이 개선될 수 있는 프로토콜을 제안한다.

논문의 전체구성은 다음과 같다. 2장에서는 관련 연구를 설명하고, 3 장은 제안 선출기법을 상세히 설명한다. 4 장은 시 뮬레이션을 통해 얻은 결과를 분석한다. 마지막으로 5 장에서 는 결론을 살펴본다.

\section{II. 관련연구}

서론에서 언급한 $\mathrm{Ad} \mathrm{Hoc}$ 네트워크의 라우팅 프로토콜 중 본 논문에서 적용되는 $\mathrm{CBRP}$ 에 대해서 살펴본다.

\section{1. 클러스터 기반 라우팅 프로토콜}

$\mathrm{CBRP}$ 는 네트워크의 모든 이동 노드들을 클러스터 단위로 나눈다. 이는 주기적인 Hello 메시지 송수신으로 얻은 이웃 노드들의 정보로 이루어진다. 클러스터는 노드의 분포에 따라 중첩되거나 분리될 수 있다. 각 클러스터는 하나의 헤드 노드 와 게이트웨이 노드, 멤버 노드들로 구성된다. 헤드 노드는 자신의 클러스터에 속한 모든 노드들의 정보를 관리한다. 클 러스터의 라우팅은 각 클러스터 헤더가 가지고 있는 정보들을 이용하여 동적으로 이루어진다. $\mathrm{CBRP}$ 는 노드들을 클러스터 단위로 관리함으로써 이동성 관리가 용이하여 제어 메시지의 오버헤드(overhead)를 줄일 수 있는 프로토콜이다.

그림 1 은 3 개의 클러스터로 형성된 $\mathrm{CBRP}$ 의 일반적인 클 러스터 구조의 예 이다. 클러스터 1은 분리되어 있으며 클러 스터 2,3 은 중첩된 형태의 클러스터이다. 클러스터 1 은 하나 의 게이트웨이 노드 $(\mathrm{G})$, 하나의 헤드 노드 $(\mathrm{H})$, 세 개의 멤버 노드로 구성된다. 게이트웨이 노드는 클러스터 헤더간의 통신 을 관리한다.

$\mathrm{CBRP}$ 는 애드 혹 네트워크의 다른 라우팅 프로토콜과는 달리 클러스터 헤더가 멤버 노드의 정보를 관리 운용함으로써 클러스터를 형성하고 유지하는 부담이 있다. 경로를 찾고자 하는 모든 멤버 노드는 클러스터 헤더를 통해 라우팅을 하기 때문에 헤더가 클러스터 밖으로 이동하거나 비정상적인 상태 가 되면 클러스터 내의 모든 이동 노드들은 새로운 헤더가 선 출될 때까지 라우팅을 멈추게 되는 문제점을 가지고 있다 〔12].

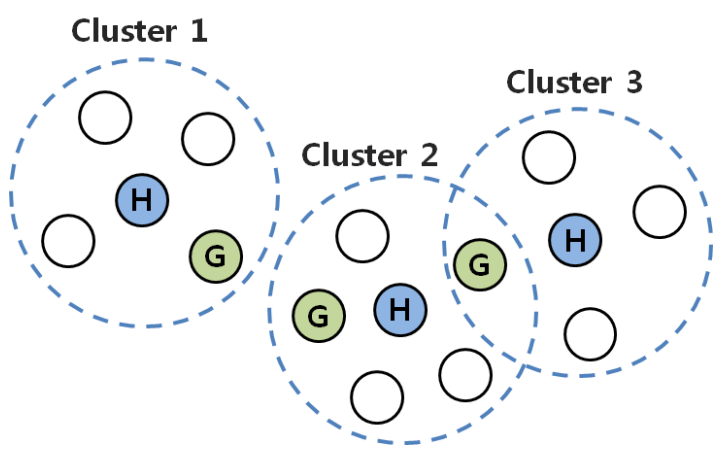

그림 1. CBRP의 일반적인 구조

Fig. 1. An Example of Cluster or CBRP

\section{2. 클러스터 헤더 선출 기법}

현재 애드 혹 네트워크를 위한 한 홉 클러스터 헤더 선출 기법에는 LID(Lowest ID) 기법과 HD(Highest Degree) 기법이 있다. LID 기법에서 각 노드는 유일한 ID가 할당된 다. 그리고 할당된 $\mathrm{ID}$ 를 주기적으로 모든 이웃 노드에게 브로 드캐스트(broadcast) 한다. 이웃 노드로부터 브로드캐스트 를 수신한 각 노드는 자신의 ID를 포함하는 ID 리스트를 가 진다. $\mathrm{ID}$ 를 비교하여 가장 낮은 $\mathrm{ID}$ 를 가진 노드가 클러스터 헤더로 선출된다. 반면에 선출된 클러스터 헤드 노드에서 단 일 홉 거리의 이웃 노드는 클러스터 멤버가 된다.

$\mathrm{HD}$ 기법에서는, 각 노드가 제어 메시지의 교환으로 자신 이 이웃한 노드의 수를 알고 있다. 이웃의 수가 가장 높은 노 드, 즉 가장 높은 등급을 가지는 노드가 클러스터 헤더가 된 다. 가장 높은 등급을 가진 노드가 여럿인 경우는 가장 낮은 $\mathrm{ID}$ 를 가지는 노드가 클러스터 헤더가 된다.

이러한 기존의 클러스터 헤더 선출 기법들은 노드의 전력 량을 고려하지 않고 클러스터 헤더를 선출하기 때문에 클러스 터 헤더의 평균 수명이 급격히 짧아진다. 그리고 헤더가 더 이상 헤더의 역할을 수행하지 못할 경우 클러스터 내의 모든 이동 노드들은 새로운 헤더가 선출될 때까지 라우팅을 멈추게 되어 전체 네트워크의 성능을 저해한다[13].

본 논문에서 제안하는 헤더 선출 기법은 전력량을 고려하 여 헤더와 보조 헤더를 선출한다. 헤더가 더 이상 자신의 역 할을 수행할 수 없을 때, 보조 헤더가 새로운 헤더 역할을 대 신 수행함으로써 전체 네트워크의 평균 수명을 연장시킨다.

\section{III. 제안 선출기법}

본 논문에서는 자신과 한 홉으로 연결된 이동 노드 중에서 
잔여전력량이 가장 높은 이동 노드를 클러스터 헤더로 선출하 고 선출된 헤더의 클러스터에서 잔여전력량이 두 번째로 높은 이동 노드를 보조 헤더로 선출하는 알고리즘을 제안한다.

클러스터 헤더를 선출하는 과정을 1 에서 보조 헤더 선출 과정은 2 에서 설명한다.

\section{1. 클러스터 헤더 선출 과정}

제안 기법에서의 클러스터 헤더 선출 과정은 $\mathrm{CBRP}$ 의 기 존 헤더선출 기법인 LID기법의 절차와 유사하다. 비컨 메시 지를 이용하여 잔여전력량 정보를 수집하고 수집된 정보를 이 용하여 잔여전력량이 가장 높은 노드를 클러스터 헤더로 선출 한다.

그림 2는 클러스터 헤더 선출을 위한 비컨 메시지 송수신 의 예를 나타낸다. 각 노드는 비컨 메시지를 교환하기 위해 자신의 잔여전력량 정보를 비컨 메시지에 기록한다. 노드 $\mathrm{F}$ 의 경우를 보면, 노드 $\mathrm{F}$ 는 한 홉으로 연결된 이웃 노드 $\mathrm{C}, \mathrm{D}$, $\mathrm{E}, \mathrm{G}, \mathrm{H}, \mathrm{I}$ 와 잔여전력량 정보가 기록된 비컨 메시지를 서로 교환한다.

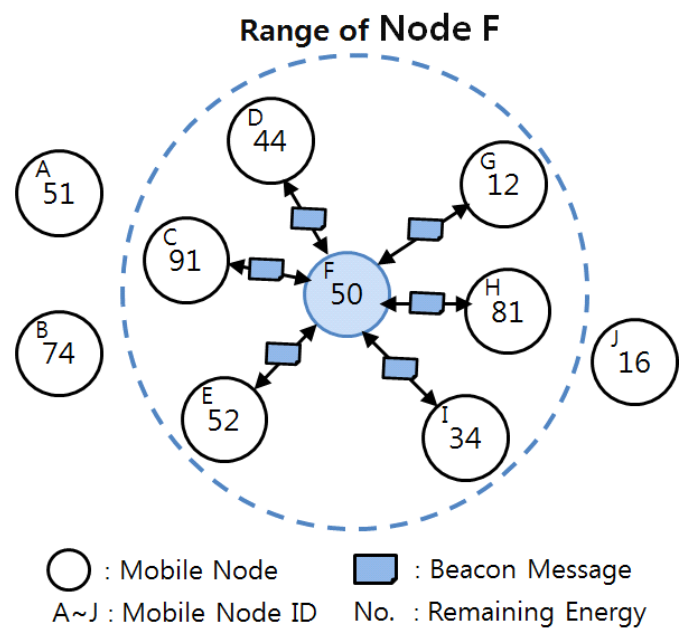

그림 2. 클러스터 헤더 선출 과정

Fig. 2. Cluster Header Electing Process

비컨 메시지 교환 결과로 모든 노드는 한 홉 거리에 존재 하는 노드들의 잔여전력량을 알게 된다. 비컨 메시지를 교환 한 모든 노드는 잔여전력량의 비교를 위해 이웃 노드들의 잔 여전력량과 자신의 잔여전력량을 자신의 이웃 테이블 (Neighbor Table)에 저장한다. 비컨 메시지에 포함된 노드 의 $\mathrm{ID}$ 정보는 $\mathrm{N} \mathrm{ID}$ 필드에 저장하고 잔여전력량 정보는 R_Energy 필드에 저장한다. N_ID 필드는 노드의 식별을 위
해 사용하고 R_Energy 필드는 가장 큰 잔여전력량을 가진 노드를 찾기 위해 사용한다. R_Energy 필드는 제안 기법의 구현을 위해 기존 $\mathrm{CBRP}$ 에서 사용하는 이웃테이블에 새로 추 가한 필드이다.

각 노드는 이웃 테이블에 저장된 R_Energy 필드를 기준 으로 내림차순으로 정렬하여 잔여전력량이 가장 높은 노드를 클러스터의 헤더의 후보로 간주한다. 만일 가장 높은 잔여전 력량의 노드가 여러 개일 경우에는 잔여전력량이 가장 많으면 서 가장 낮은 $\mathrm{ID}$ 를 가진 노드를 클러스터 헤더의 후보로 간주 한다. 다음으로 클러스터 헤더 후보의 ID(NID)를 자신의 $\mathrm{ID}$ 와 비교한다. N_ID가 자신의 ID와 같으면 자신이 클러스 터의 헤더가 되고 다르면 N_ID 값에 해당하는 노드가 클러스 터 헤더가 된다. 선출된 헤더를 중심으로 한 홉 거리에 있는 노드들이 클러스터를 형성한다.

그림 3은 노드 $\mathrm{F}$ 가 이웃 노드로부터 수신한 비컨 메시지 에 있는 잔여전력량과 자신의 잔여전력량을 저장하여 R_Energy를 기준으로 정렬한 이웃 테이블의 예를 나타낸다. 정렬된 값 중에서 노드 $\mathrm{C}$ 가 이웃 테이블에서 가장 큰 R_Energy를 가지는 노드이다. 그래서 노드 C가 클러스터 헤 더 후보가 된다. 다음으로 클러스터 헤더 후보의 N_ID(노드 $\mathrm{C}$ )와 자신의 $\mathrm{ID}($ 노드 $\mathrm{F}$ )가 같은지를 비교한다. 두 ID가 같 지 않기 때문에 $\mathrm{C}$ 를 자신이 속한 클러스터의 헤더로 선출한 다. 최종적으로 노드 $\mathrm{C}$ 는 클러스터의 헤더가 되고 노드 $\mathrm{F}$ 는 노드 $\mathrm{C}$ 를 중심으로 하는 클러스터의 멤버 노드가 된다.

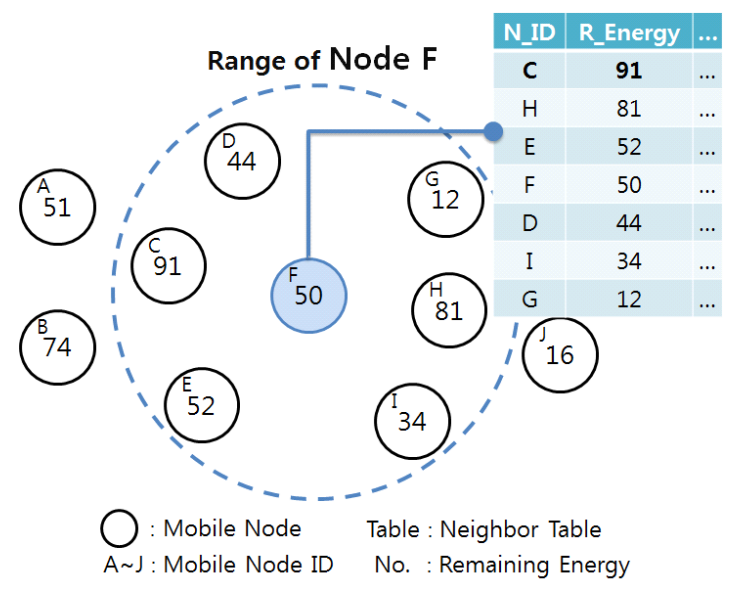

그림 3. 클러스터 헤더 선출

Fig. 3. Cluster Header Electing

각 클러스터 내에 헤더가 선출되면 이동 노드들은 자신과 
한 홉 거리에 있는 헤더의 클러스터에게 가입되어 클러스터 내의 멤버 노드가 되고 선출된 헤더는 모든 멤버 노드들을 관 리 및 운영한다.

그림 4에서 음영 처리된 노드 $\mathrm{C}$ 와 $\mathrm{H}$ 는 선출된 클러스터 헤더를 나타낸다. 각 노드들이 헤더 선출 과정을 거쳐 클러스 터 1 에서 가장 높은 잔여전력량을 가진 노드 $\mathrm{C}$ 와 클러스터 2 에서 가장 높은 잔여전력량을 가진 노드 $\mathrm{H}$ 가 헤더로 선출된 다. 이때, 노드 $\mathrm{F}$ 는 두 클러스터 1,2 에 속하면서 클러스터 1,2 간의 통신을 담당하는 게이트웨이 노드가 된다. 결과적 으로 그림 4 와 같이 노드 $\mathrm{F}$ 를 게이트웨이 노드로 하는 중첩 된 클러스터 2 개가 형성된다.

제안 프로토콜에서는 위와 같은 과정을 거쳐 클러스터 헤 더를 선출하고 클러스터를 형성한다. 클러스터를 형성한 후 클러스터 보조 헤더를 선출한다.

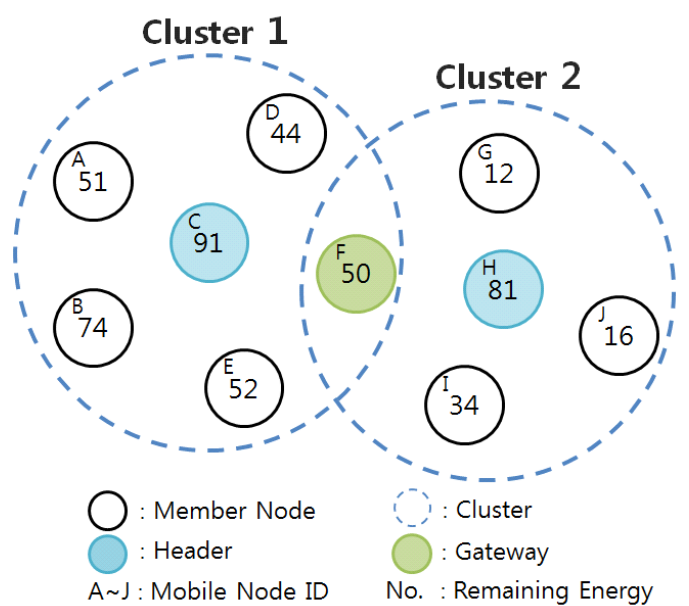

그림 4. 클러스터 형성

Fig. 4. Cluster Formation

\section{2. 클러스터 보조 헤더 선출 과정}

클러스터를 형성하고 난 뒤 각 클러스터의 헤더는 동일한 클러스터 내에서 잔여전력량이 두 번째로 높은 노드를 보조 헤더로 선출한다. 보조 헤더의 선출에는 헤더의 이웃 테이블 에 있는 N_ID 필드, R_Energy 필드 그리고 클러스터를 구 분하는 $\mathrm{C} \mathrm{ID}$ 필드가 사용된다. 선출된 헤더의 $\mathrm{C} \mathrm{ID}$ (클러스 터_ID)와 동일하면서 잔여전력량이 두 번째로 높은 노드를 보조 헤더로 선출한다.

그림 5 와 같이 클러스터 1 의 헤드 노드인 $\mathrm{C}$ 는 자신의 이 웃 테이블에서 C ID 필드를 이용하여 동일한 클러스터 내에 존재하는 멤버 노드를 식별한다. 자신의 멤버 노드들 중 잔여 전력량이 두 번째로 높은 노드 $\mathrm{B}$ 를 클러스터 1 의 보조 헤더
로 선출한다.

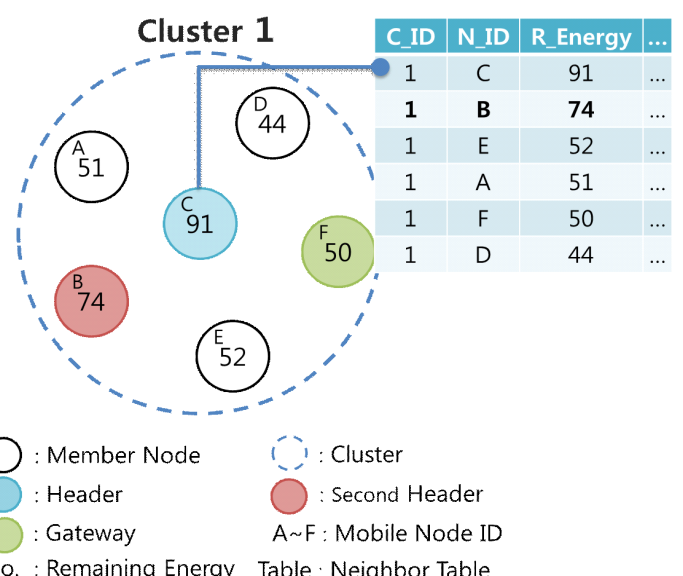

그림 5. 클러스터 보조 헤더 선출

Fig. 5. Cluster Second Header Electing

기존 클러스터 헤더의 잔여전력량이 낮아져 더 이상 헤더 역할을 수행할 수 없게 되면 헤더는 멤버 노드들에게 비컨 메 시지를 전송한다. 헤더는 자신의 상태를 알린 다음 미리 선출 해둔 보조 헤더에게 클러스터 헤더 역할을 하게하고 보조 헤 더를 중심으로 새로운 클러스터를 형성한다. 주기적인 비컨 메시지의 교환을 통해 새로운 클러스터 내의 헤더보다 더 높 은 잔여전력량을 가진 노드가 멤버로 가입되더라도 기존의 보 조 헤더는 헤더의 역할을 계속 수행한다. 새로운 클러스터가 형성될 때 배제된 멤버 노드들은 다른 노드들과 새로운 클러 스터를 형성하거나 단일 클러스터가 된다.

그림 6과 같이 헤드 노드 $\mathrm{C}$ 의 잔여전력량이 낮아져 더 이 상 헤더 역할을 수행할 수 없다고 판단되면 노드 $\mathrm{C}$ 는 클러스 터 멤버 노드들과 게이트웨이 노드에게 비컨 메시지를 이용해 자신의 상태를 알린다. 그런 다음, 미리 선출해둔 보조 헤더 B 가 헤더의 역할을 수행하도록 한다. 보조 헤더인 노드 $\mathrm{B}$ 는 새 로운 헤더가 되고 이를 중심으로 새로운 클러스터가 형성된다.

새로운 헤더 $\mathrm{B}$ 는 그림 5 와 같이 자신의 클러스터 내의 보 조 헤더를 선출해 두고 자신이 더 이상 헤더의 역할을 할 수 없게 되면, 그림 6 과 같이 보조 헤더가 헤더의 역할을 수행하 도록 한다. 


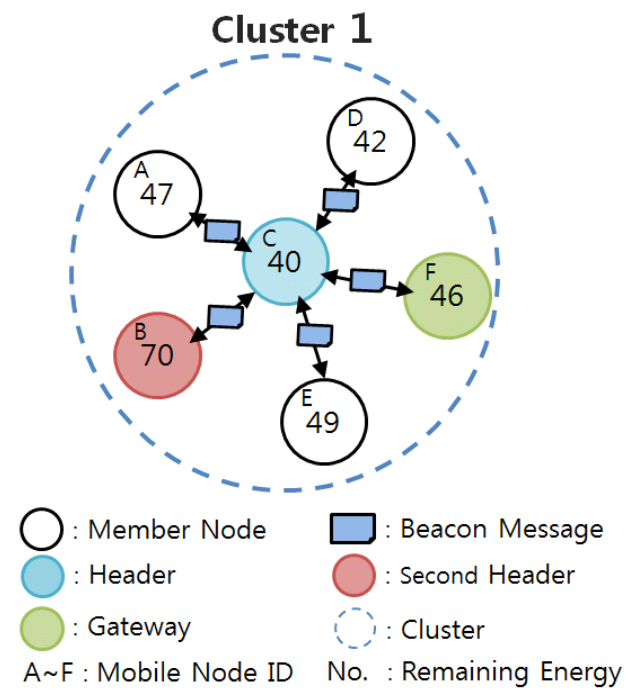

그림 6. 클러스터 헤더 알림 과정

Fig. 6. Cluster Header Notify Process

이웃 노드의 정보는 비컨 주기 동안 수집한다. 비컨 주기 가 끝나면 이웃 노드의 정보가 충분히 수집되었다고 판단하여 헤더 선출 알고리즘을 시작한다.

그림 7은 클러스터 헤더 선출 알고리즘이다. 클러스터 헤 더 선출 시 이웃 테이블에 저장된 잔여전력량을 내림차순 정 렬한다. 노드 자신이 클러스터 헤더인지의 여부를 확인하기 위해서 첫 번째 엔트리의 ID(N_ID)를 자신의 ID와 비교한 다. N_ID가 자신의 ID와 같으면 자신이 클러스터의 헤더가 되고 N_ID가 지신의 ID와 같지 않으면 N_ID 값에 해당하는 노드가 클러스터 헤더로 선출된다.

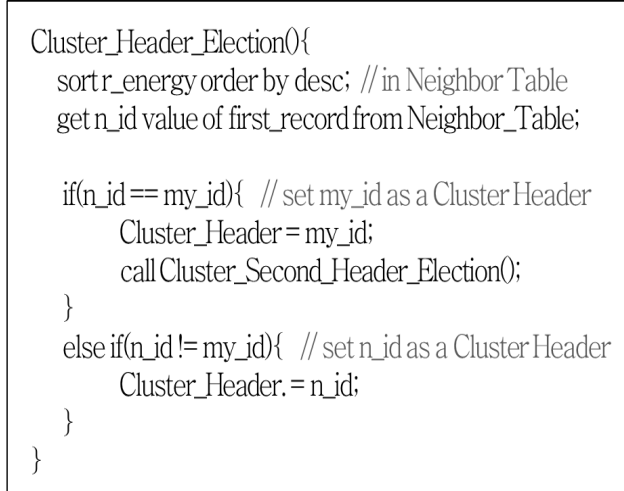

그림 7. 클러스터 헤더 선출 알고리즘

Fig. 7. Cluster Header Election Algorithm

클러스터 헤더를 선출하고 난 뒤 각 클러스터의 헤더는 자 신이 속한 클러스터 내에서 잔여전력량이 두 번째로 높은 노 드를 보조 헤더로 선출한다.

선출된 클러스터 헤더가 노드 자신인 경우 그림 8의 클러 스터 보조헤더 선출 알고리즘을 실행한다. 노드 자신의 C_ID(클러스터_ID)와 동일하면서 잔여전력량이 두 번째로 높은 노드를 보조 헤더로 선출한다.

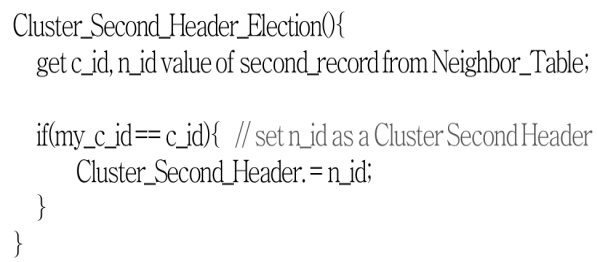

그림 8. 클러스터 보조헤더 선출 알고리즘

Fig. 8. Cluster Second Header Election Algorithm

제안된 클러스터 헤더 선출 기법은 전력을 고려하여 헤더 와 보조 헤더를 선출하기 때문에 클러스터 헤더의 전력이 고 갈될 경우 헤더가 선출될 때까지 수행을 멈추게 되는 문제점 을 미연에 방지한다.

헤더가 더 이상 역할을 할 수 없는 경우 보조 헤더가 헤더 역할을 하여 클러스터의 재구성이 빠르게 일어나 헤더 선출 지연을 줄인다. 잔여전력량이 가장 높은 노드가 헤더로 선출 되기 때문에 각 클러스터의 모든 노드는 전력이 균등하게 소 비되어 노드와 네트워크 전체 수명이 향상된다.

\section{IV. 시뮬레이션}

본 논문에서는 기존 $\mathrm{CBRP}$ 와 제안 프로토콜의 효율성을 비교하고 평가하기 위해 표 1 과 같은 환경에서 시뮬레이션을 수행한다. 
표 1. 시뮬레이션 환경

Table 1. Simulation Environment

\begin{tabular}{|c|c|}
\hline Parameters Name & Parameters Value \\
\hline Protocol & CBRP, Proposed Protocol \\
\hline Simulation time & 500 \\
\hline Simulation area & $1000 \mathrm{~m}^{*} 1000 \mathrm{~m}$ \\
\hline Nodes number & 100 \\
\hline Transmission range & 100 \\
\hline Node speed & $\begin{array}{c}\text { 0 20m/s } \\
\text { Two-ray } \\
\text { Propagation model }\end{array}$ \\
\hline Packet type & \begin{tabular}{c} 
UDP, CBR \\
\hline
\end{tabular} \\
\hline
\end{tabular}

기존 $\mathrm{CBRP}$ 는 잔여전력량을 고려하지 않고 가장 낮은 $\mathrm{ID}$ 를 가진 노드를 헤더로 선출하기 때문에 동일한 노드가 반복 적으로 선출되며 에너지가 급격히 줄어들어 수명이 단축된다. 반면, 제안 프로토콜은 잔여전력량을 고려하여 잔여전력량이 가장 높은 노드가 헤더가 되기 때문에 네트워크의 전체 수명 이 향상된다.

그림 9는 시간에 따른 생존 노드의 비율로 기존 $\mathrm{CBRP}$ 에 비해 제안 기법에서 더 많은 노드가 생존해 있음을 보여준다. 기존 $\mathrm{CBRP}$ 는 약 50 초부터 노드의 수가 급속도로 줄어들지 만 제안 프로토콜은 약 100 초부터 노드의 수가 완만하게 줄 어든다.

시뮬레이션의 종반부에서 적은 수의 생존 노드가 라우팅을 지속적으로 수행하기 때문에 제안 기법에서의 생존 노드의 수 도 감소한다. 표 2에서 생존 노드의 비율에 대한 시뮬레이션 결과 값을 비교하여 향상된 성능을 보여준다. 결과적으로 전 체 네트워크의 수명이 향상됨을 알 수 있다.

그림 10은 시간에 따른 누적 헤더 재선출 횟수로 기존 $\mathrm{CBRP}$ 에 비해 제안 선출 기법의 헤더 재선출 횟수가 더 적음 을 보여준다. 시뮬레이션 초반부에는 기존 $\mathrm{CBRP}$ 와 제안 선 출 기법의 헤더 재선출 횟수의 차이가 크지 않음을 보여준다. 하지만 종반부로 갈수록 기존 $\mathrm{CBRP}$ 보다 제안 선출 기법의 헤더 재선출 횟수가 보조 헤더로 인해 빠르게 감소한다.

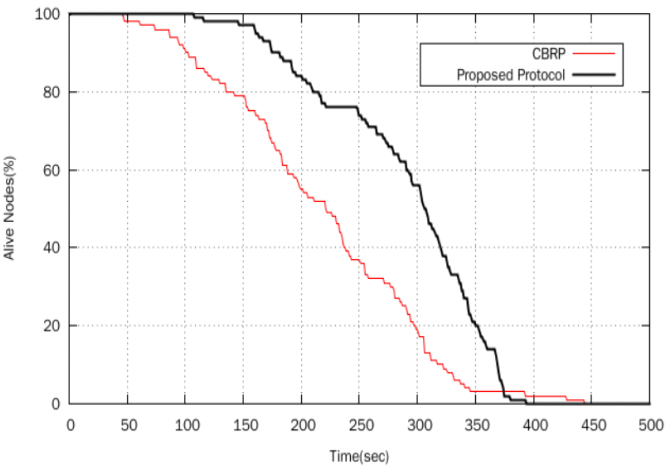

그림 9. 생존 노드의 비율

Fig. 9. Percentage of Alive Nodes

표 2. 시뮬레이션 결과 값

Table 2. Simulation Result

\begin{tabular}{|c|c|c|}
\hline \multirow{2}{*}{} & \multicolumn{2}{|c|}{ 생존 노드의 비율 } \\
\cline { 2 - 3 } & CBRP & Proposed Protocol \\
\hline 50 s & 98 & 100 \\
\hline 150 s & 79 & 97 \\
\hline 250 s & 37 & 74 \\
\hline 350 s & 3 & 20 \\
\hline
\end{tabular}

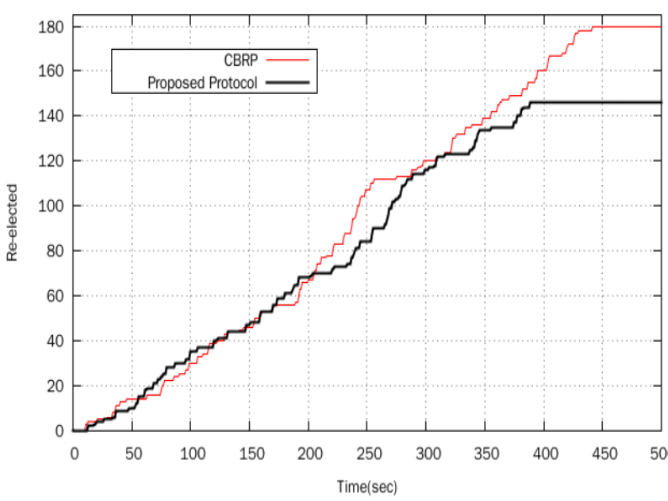

그림 10. 헤더 재선출 횟수

Fig. 10. Number of Re-electing The Cluster Header

그림 11 은 $\mathrm{CBRP}$ 의 기존 선출 기법과 제안 선출 기법의 노드별 전력 소비를 비교한다. 위의 시뮬레이션 환경과는 다 르게 노드의 수는 10 개로 하고 시뮬레이션 시간은 100 초로 한다. 그래프의 $\mathrm{x}$ 축은 노드의 ID를 나타내고 $\mathrm{y}$ 축은 각 노드 의 에너지를 나타낸다. 각 노드의 시뮬레이션 초기 잔여전력 
량과 50초, 100초 후의 잔여전력량을 나타낸다. 그림 11 (a)에서 기존 선출 기법의 결과는 불균형한 에너지 소비로 인 해 몇몇 노드가 죽었음을 보여준다. 반면 그림 11 (b)에서 제 안 선출 기법은 죽은 노드 없이 균등한 에너지 소비를 보여준 다.

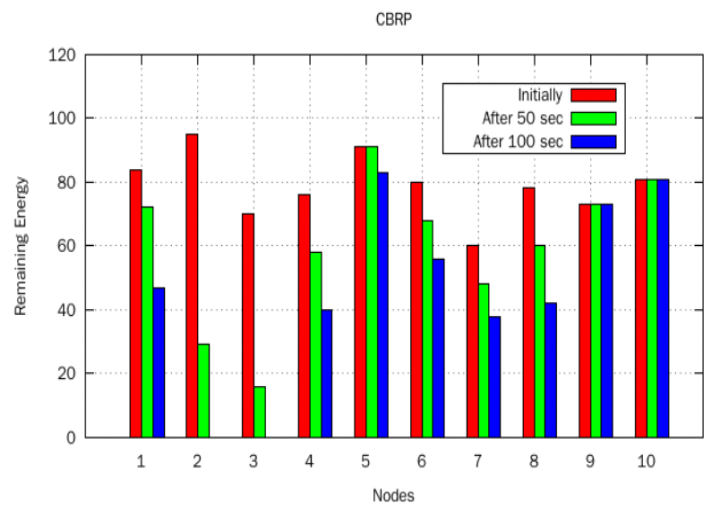

(a) 기존 선출기법의 잔여전력량

(a) The Remaining Energy of The Existing CBRP

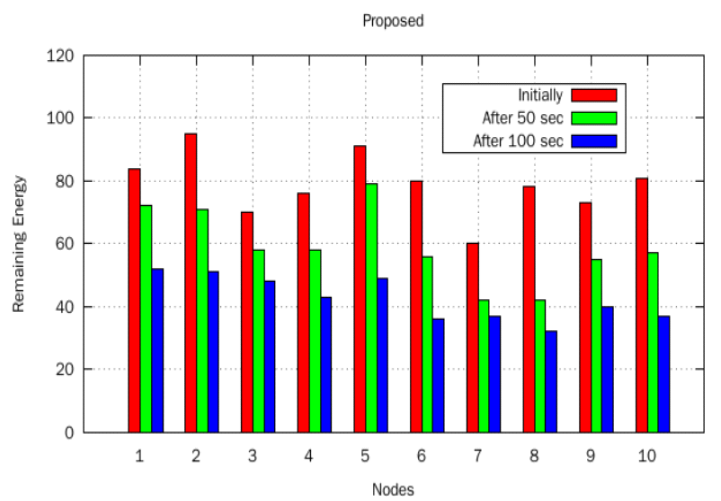

(b) 제안 선출기법의 잔여전력량

(b) The Remaining Energy of The Proposed CBRP

그림 11. 잔여전력량 비교

Fig. 11. Comparison of Remaining energy

\section{V. 결론}

기존 $\mathrm{CBRP}$ 의 클러스터 헤더 선출 기법은 노드의 전력을 고려하지 않고 헤더를 선출하여 헤더의 수명이 짧아지고 헤더 재선출을 빈번하게 일으키는 문제점을 가지고 있다.

본 논문에서 제안한 프로토콜에서는 노드의 잔여전력량을
고려하여 헤더와 보조헤더를 선출한다. 헤더 노드를 선출하기 위해서 각 노드는 자신과 한 홉으로 연결된 이웃 노드들의 잔 여전력량 정보가 포함된 비컨 메시지를 교환한다. 수신한 비 컨 메시지에 있는 잔여전력량 정보를 이용하여 가장 높은 잔 여전력량을 가진 노드를 헤더로 선출한다. 그리고 선출된 헤 더의 클러스터 내에서 잔여전력량이 두 번째로 높은 노드를 보조 헤더로 두어 헤더 자신이 더 이상 헤더 역할을 할 수 없 을 때 헤더 역할을 보조 헤더에게 넘겨 클러스터의 재구성이 빠르게 일어나도록 한다.

제안 기법은 기존의 문제점을 개선하여 클러스터 헤더의 수명을 향상시키고 빈번하게 일어나던 헤더 재선출 문제가 줄 어든다. 따라서 전체 네트워크 수명이 향상되고 경로의 안정 성이 높아진다.

\section{참고문헌}

〔1] Kyung-In Kang, Gyong-Bae Park, "Traffic Management in Mobile Ad-hoc Network," 『Journal of the Korea society of computer and information $\sqrt{ }$, Sep. 2011.

[2] Charles E. Perkins, Bhagwat P, "Highly dynamic destination-sequenced distance-vector routing (DS- DV) for mobile computers," In proceedings of ACM Sigcomm, October, 1994.

[3] Charles E. Perkins, Elizabeth M. Belding Royer, and Samir R. Das, "Ad Hoc On-demand Distance Vector (AODV) Routing," IETF Internet Draft: draft-ietf- manet-aodv-12.txt, Nov. 2002.

[4] Johnson D, Maltz D, "Dynamic source routing in ad hoc wireless network," In Computer Communication Review, Proceedings of SIGCOMM, Aug. 1996.

[5] V. Park, S. Corson, "Temporally-Ordered Routing Algorithm(TORA) Version 1," Internet Draft draft- ietf-manet-tora-spec-04.txt, July, 2001.

[6] Zygmunt J. Haas, Marc R. Pearlman, Prince Samar, "The Zone Routing Protocol(ZRP) for Ad Hoc Net- works," Internet Draft draft-ietf-manet-zone- zrp-04.txt, July, 2002.

[7] M. Jiang, J. Li, Y. C. Tay, "Cluster Based Routing Protocol(CBRP)," Internet Draft draft-ietf-manet- cbrp-spec-01.txt, Aug. 1999.

[8] Cheong-Yeop Lee, Yong-Hyeon Shin, "An Energy- 
aware Dynamic Source Routing Algorithm for Mobile Ad-hoc Networks," "Journal of the Korea society of computer and information』Vol. 16 No. 10, October, 2011.

[9] Jinman Jung, Bongjae Kim, Junhyuk Jang, Hong Min, Yookun Cho, Jiman Hong, Junyoung Heo, "Mobility- Based Energy Analysis of Routing Schemes for MANETs," "The Korean Institute of Information Scientists and Engineers』Vol. 17 No. 5, May, 2011.

〔10] Jin-Su Kim, Seung-Soo Shin, “An Energy Consumption Model using Hierarchical Unequal $\mathrm{Clu}^{-}$stering Method," 『Journal of the Korea Academia- Industrial comoperation Society』 Vol. 12 No. 6, June, 2011.

[11] Charles E. Perkins, "Ad Hoc Networking," $\mathrm{Ad}^{-}$ dison-Wesley, pp.75-138, Dec. 2000.

〔12] Tae-sung Hur, "An efficient cluster-based routing protocol using secondary header in mobile Ad Hoc networks," Inha University, July, 2002.

[13] Hyeksu Kim, Junho Hwang, Myungsik Yoo, "A Stable Clustering Scheme Based on Node Mobility for Mobile Ad Hoc Networks," The Korean Institute of Communications and Information Sciences, Vol. 34 No. 5, May, 2009.

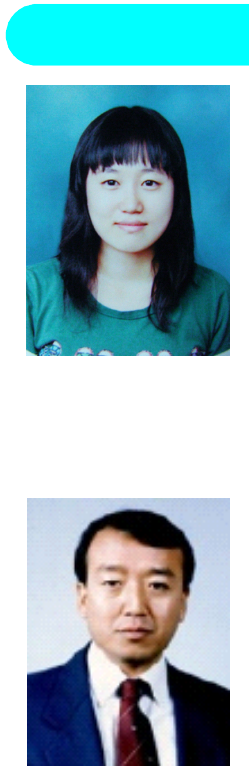

\section{저 자 소 개}

박혜란(Hyeran Park)

2011년 경남대학교

컴퓨터공학과 공학사

2011년 경남대학교 첨단공학과 석사과정

관심분야 : Ad-hoc Networks

Email : enticergirl@gmail.com

\section{김우완(Wuwoan Kim)}

1990년 12월 Texas A\&M University, ELEN (공학석사)

1995년 8월 Texas A\&M University, ELEN (공학박사)

1996년 3월 현재 경남대학교 컴퓨터공학과 교수

관심분야 : 이동 컴퓨팅/네트워킹

Email : wukim@kyungnam.ac.kr

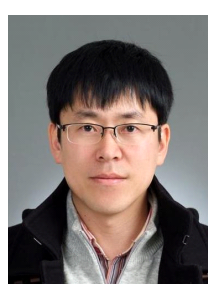

장상동(Sangdong Jang)

1997년 2월 경남대 전산통계학과 (이학사)

1999년 2월 경남대 컴퓨터공학과 (공학석사)

2005년 2월 경남대 컴퓨터 공학과 (공학박사)

2012년 3월 현재 경남대학교

컴퓨터공학과 조교수

관심분야 : 이동 컴퓨팅, 센서네트워크 Email : angong@kyungnam.ac.kr 